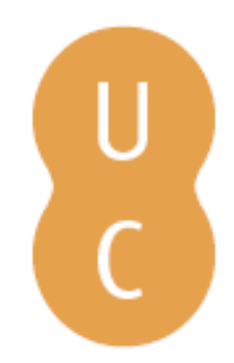

\title{
pompalina
}

\section{A construção do império na Hispânia: contrastes nas narrativas da conquista romana do Ocidente}

\author{
Autor(es): $\quad$ Guerra, Amílcar \\ Publicado por: Imprensa da Universidade de Coimbra \\ URL \\ persistente: URI:http://hdl.handle.net/10316.2/45225 \\ DOI: $\quad$ DOI:https://doi.org/10.14195/978-989-26-1626-1_16 \\ Accessed : $\quad$ 26-Apr-2023 16:28:46
}

A navegação consulta e descarregamento dos títulos inseridos nas Bibliotecas Digitais UC Digitalis, UC Pombalina e UC Impactum, pressupõem a aceitação plena e sem reservas dos Termos e Condições de Uso destas Bibliotecas Digitais, disponíveis em https://digitalis.uc.pt/pt-pt/termos.

Conforme exposto nos referidos Termos e Condições de Uso, o descarregamento de títulos de acesso restrito requer uma licença válida de autorização devendo o utilizador aceder ao(s) documento(s) a partir de um endereço de IP da instituição detentora da supramencionada licença.

Ao utilizador é apenas permitido o descarregamento para uso pessoal, pelo que o emprego do(s) título(s) descarregado(s) para outro fim, designadamente comercial, carece de autorização do respetivo autor ou editor da obra.

Na medida em que todas as obras da UC Digitalis se encontram protegidas pelo Código do Direito de Autor e Direitos Conexos e demais legislação aplicável, toda a cópia, parcial ou total, deste documento, nos casos em que é legalmente admitida, deverá conter ou fazer-se acompanhar por este aviso.

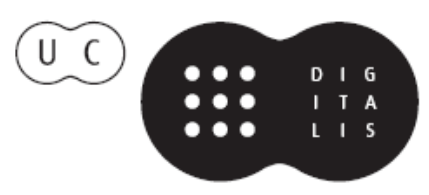




\section{Arqueologias de Império}

\section{Delfim Leão, José Augusto Ramos, Nuno Simões Rodrigues (coords.)}

IMPRENSA DA UNIVERSIDADE DE COIMBRA 


\title{
A CONSTRUÇÃo DO IMPÉRIO NA HisPÂNIA: CONTRASTES NAS NARRATIVAS DA CONQUISTA ROMANA DO OCIDENTE ${ }^{1}$ (Building the empire in Hispania: contrasts amongst the narratives on the Roman conquest of the West)
}

\author{
Amílcar Guerra \\ (aguerra@campus.ul.pt; ORCID: 0000-0003-3478-0036) \\ Universidade de Lisboa, Faculdade de Letras, CH-ULisboa e UNIARQ
}

Resumo - A imagem que a historiografia antiga apresenta do processo de construção do imperialismo romano e dos seus intervenientes depende, inevitavelmente, de uma perspetiva enformada pela cultura grega e latina e pelos seus paradigmas. Deste modo, o quadro que se transmite dos povos hispânicos deve ser sempre lido nessa chave, apresentando-se em oposição àqueles, numa dicotomia que com frequência se associa à oposição entre civilização e barbárie. Constata-se, de qualquer modo, que a visão desse mundo não é necessariamente plana. Dispomos de um número considerável de exemplos que ilustram a complexidade desse panorama. Neste sentido, apresentam-se alguns exemplos em que de alguma forma se enuncia uma imagem reversa: por um lado, a arenga de Aníbal aos seus soldados antes da batalha do Ticino, em que o general apresenta a sua perspetiva sobre o comportamento dos romanos; por outro, referem-se alguns episódios em que se põe em evidência o heroísmo de mulheres hispânicas, a começar pelo que ocorre entre os Brácaros no contexto da campanha galaica de Décimo Júnio Bruto.

Palavras-chave: Imperialismo romano; Hispânia; Décimo Júnio Bruto; Aníbal.

AвstraCt - The ancient historiography offers an image of the Iberian conquest process and its actors according to a perspective shaped by Greek and Latin culture and its models. Thus, the portrait of the Hispanic peoples transmitted by the ancient sources must always be interpreted on this key, i. e., as a dichotomy between civilization and barbarism. However, the view of this other world is not necessarily plain. We have a considerable number of examples illustrating the complexity of the circumstances emerging of classical sources. With this proposal we will analyse some examples in which a reverse of the ordinary perspective is offered: Hannibal's harangue to his soldiers before the battle of Ticinus; and some episodes that highlight the heroism of Hispanic women.

KEYwORDs: Roman imperialism; Hispania; Decimus Junius Brutus; Hannibal.

\footnotetext{
${ }^{1}$ Este trabalho foi apoiado por Fundos Nacionais através da FCT - Fundação para a Ciência e a Tecnologia no âmbito do projeto UID/HIS/04311/2013.
} 


\section{INTRODUÇÃO}

Quando se aborda a questão das fontes relativa à história da Hispânia romana, percebe-se de imediato a amplitude e importância dos textos que se reportam a essa fase marcada essencialmente pelas movimentações político-militares associadas à conquista do território. Trata-se, é certo, de um período bastante longo, que abarca cerca de dois séculos, se considerarmos o lapso de

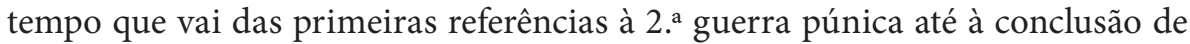
todo o processo, com as guerras contra Cântabros e Ástures. Sem ignorar aspetos relevantes para compreender a história, geografia e etnologia da Hispânia, sobressai a informação sobre as múltiplas ações militares desse período, centradas não apenas no lado romano, mas descrevendo igualmente as técnicas e estratégias de combate dos povos hispânicos, bem como todo o contexto político e «diplomático» que as enquadra.

Não surpreende, neste repositório, que a narrativa sobre os conflitos se alinhe por uma perspetiva romana ou, mais propriamente, por uma forma de ver imbuída de uma cultura greco-latina que domina o mundo mediterrâneo. Se os textos sublinham por vezes a admiração pelo desenvolvimento de umas regiões ribeirinhas do Mediterrâneo, assinalam, por outro lado, alguma estranheza em relação a um universo que não se enquadra nessa esfera. E neste caso se encontram as regiões setentrionais e ocidentais da Hispânia.

Este contributo visa explorar precisamente esse contraste cultural e forma como alguns autores clássicos o exprimem, apresentando-o, de forma mais ou menos explícita, como sinais da superioridade civilizacional do imperialismo romano. Dada a impossibilidade de analisar genericamente um tema tão complexo no âmbito de um contributo necessariamente bastante reduzido, selecionaremos alguns quadros específicos que de alguma forma proporcionam uma visão diferenciada da realidade hispânica no período da conquista.

Trataremos, de forma necessariamente breve, da análise de textos de autores latinos, como Tito Lívio, Floro e Orósio, mas também de língua grega, como Apiano, Políbio, Plutarco, procurando analisar alguns aspetos que se prendem com a forma de olhar para os diversos agentes deste processo expansionista romano, cuja natureza é sempre apreciada numa perspetiva externa. A escolha destes autores e de alguns dos seus textos pretende ilustrar, de qualquer modo, a diversidade de pontos de vista sobre os intervenientes e a complexidade que pode apresentar a representação destas realidades locais².

\footnotetext{
${ }^{2}$ As relações entre o imperialismo romano e o seu confronto com as entidades locais, na perspetiva de diferentes autores clássicos, constituem um tópico largamente analisado. Para um âmbito mais geral pode ver-se, ultimamente, Revell 2009; para o caso específico da Península Ibérica, dispomos de uma abundante literatura: García Moreno 1987, 1989, 2005; Gómez Espelosín 1993, 2009; García Quintela 1999; Salinas 1999, 2002, 165-80; Pelegrín 2003; Gracia 2009; Hernández Prieto 2011; Aguilera 2012.
} 
A superioridade da cultura greco-romana constitui, naturalmente, um dos tópicos que marcam a historiografia antiga, emergindo com clareza a dicotomia entre esse universo e o que não se enquadra nele. A forma de encarar essa oposição é tratada pelo próprio Estrabão, em especial nas reflexões que encerram o livro I da sua Geografia. É significativo que ele aí exprima a sua oposição a uma perspetiva distinta, com tradição no pensamento grego ${ }^{3}$. Refere explicitamente a sua oposição a Eratóstenes, o qual não concordava com uma visão histórica em que se opunha grego a bárbaro ${ }^{4}$, sublinhando o geógrafo alexandrino que há plena justificação nessa diferença, uma vez que temos, por um lado, sociedades que se regem pela lei, pela educação e pela razão ( $\lambda o ́ \gamma \omega v$ ); por outro, comunidades que representam todo o contrário.

Esta oposição, que pode ser mais evidente em Estrabão, é precisamente contrária à prática de Alexandre Magno, como se diz no passo referido, e matizada, como se verá, em outros autores, dando-se aqui especial destaque a Apiano.

De qualquer modo, mesmo que pontualmente possa sublinhar-se a dignidade dos povos peninsulares, nunca parece questionável a supremacia romana. Esta não resulta unicamente da sua elevada capacidade militar, mas genericamente do seu modo de vida, da sua cultura, refletida em muitos aspetos da organização social e política e emergindo tanto nas estratégias de guerra, na sua conceção do bellum iustum, como nos domínios da diplomacia, da sua relação com os povos hispânicos. Mas, acima de tudo, essa superioridade é de natureza ética, isto é, pauta o seu comportamento por valores distintos, sólidos e estáveis. À semelhança do que se pedia a qualquer cidadão na sua vida privada e pública, também se pedia aos governantes e aos generais o respeito pelos princípios que definiam o modelo do cidadão.

Essa realidade cultural insere-se na tradição da história e etnografia gregas de período tardo-republicano e alto-imperial e, por essa razão, os textos dão conta com frequência de casos concretos que demonstram que a cultura da urbe se sobrepunha à dos povos dominados. Um desses exemplos, evocado tantas vezes pela historiografia moderna, reside no episódio da conquista de Lancia, uma notável cidade dos Ástures e um dos últimos redutos deste povo. As narrativas paralelas de Floro e Orósio, dão conta de um episódio ilustrativo, que se enquadra bem na tradição romana de promover as virtudes dos seus generais e sua superioridade moral:

\footnotetext{
${ }^{3}$ Este texto e as suas implicações foi analisado, tendo em conta a realidade hispânica, em Plácido (1989, 252-53).

${ }^{4}$ É muito ampla a investigação que explora esta oposição como perspetiva de análise do mundo antigo, entre eles Dauge 1981, Thollard 1987, Hall 1989 e Woolf 2011; em relação à Hispânia em particular v. Bermejo Barrera 1986, Duplá et al. 1988, Pelegrín 2003, González Ballesteros 2009 e Aguilera Durán 2012.
} 
«A valorosa cidade de Lância acolheu o remanescente do exército destroçado, onde se combateu a tal ponto com as dificuldades do terreno que, quando se reclamava o incêndio da cidade já tomada, a muito custo o general conseguiu compreensão para o facto de esta ser mais alto testemunho da victória de Roma mantendo-se assim que incendiada $»^{5}$.

A narrativa de Orósio é semelhante: »/.../ e quando os soldados se preparavam para atacarem pelo fogo a cidade sitiada, o comandante Carísio por um lado pediu aos seus que pusessem termo ao incêndio e por outro exigiu dos bárbaros a declaração de rendição - é que procurava, com empenho, deixar a cidade inteira e preservada como testemunho da sua victória ${ }^{6} »$.

Como se tem sublinhado, no contexto das narrativas que refletem bem os efeitos de uma eficiente ação propagandística de Augusto ${ }^{7}$, estes aspetos particulares constituem elementos sugestivos e perfeitamente adequados aos objetivos do princeps.

\section{O OLHAR REVERSO SOBRE O IMPERIALISMO ROMANO: A ARENGA DE} Aníbal.

A literatura clássica não deixa, todavia, de apresentar de certa forma o contraponto dessa superioridade romana. Quer seja por efeito retórico, quer na sequência de uma visão mais realista deste universo dos povos em conflito com Roma, não faltam elementos que dão conta de uma outra perspetiva de encarar o domínio romano.

Um dos mais sugestivos passos a este respeito colhe-se no célebre discurso que Aníbal pronuncia aos seus soldados depois da passagem dos Alpes, na iminência de enfrentarem e derrotarem o inimigo na batalha do Ticino. Como tem sido referido, este célebre texto, elaborado por Tito Lívio de acordo com os mais consagrados modelos retóricos ${ }^{8}$, coloca na boca do general cartaginês o que deveriam ser alguns dos argumentos que se poderiam invocar contra $o$ comportamento «imperialista» da Urbe:

«Povo cruel e soberbo, tudo faz seu e segundo o seu arbítrio; pensa que é justo impor-nos com quem havemos de estar em guerra, com quem em paz;

${ }^{5}$ Reliquias fusi exercitus ualidissima ciuitas Lancia excepit, ubi cum locis adeo certatum est, ut, cum in captam urbem faces poscerentur aegre dux impetrauerit ueniam. (58) ut uictoriae Romanae stans potius esset quem incensa monumentum (Flor. 2.33.57-58)

$6 / . . /$ cumque milites circumdatam urbem incendio adoriri pararent, dux Carisius et a suis cessationem impetrauit incendii et a barbaris uoluntatem deditionis exegit. studiose enim nitebatur integram atque incolumem ciuitatem uictoriae suae testem relinquere (Oros. 6.21.10).

${ }^{7}$ Sobre este tópico v. Salinas 1998.

${ }^{8}$ Uma recente análise sob esta perspetiva retórica pode encontrar-se em Manchón Gómez 2013. 
circunscreve-nos e encerra-nos em limites de montes e vales que não podemos ultrapassar e que nem sequer respeita as fronteiras que estabelece»`.

E invoca de seguida as afrontas mais recentes da fronteira do Ebro e da questão saguntina, recordando, ao mesmo tempo, o roubo da Sardenha e da Sicília.

Ainda que se trate, como se disse, de uma peça retórica, o patavino não deixa de pôr em relevo dois aspetos que marcam o comportamento de Roma e que se encontram bem documentados nos relatos de guerra referentes à Hispânia: a imposição de exigências às comunidades locais, por vezes aparentemente injustificadas ou não suficientemente explícitas, nomeadamente de ordem territorial, e o incumprimento dos tratados que a própria Roma subscreve.

$\mathrm{Na}$ literatura referente às guerras na Hispânia encontra-se com frequência a expressão concreta dessa política de fixação das populações, da determinação de um território e das respetivas fronteiras ou da imposição de restrições no domínio territorial. Uma das mais relevantes consequências desta política manifesta-se no crónico problema da "falta de terras» e que se encontra insistentemente referida no caso dos Lusitanos, mas também em outras entidades. Um exemplo ilustrativo pode encontrar-se num famoso passo de Apiano (Hisp. 59) no qual se transcreve a explicação de Galba para o permanente conflito com este povo: «/.../ a esterilidade do solo, disse, e a pobreza vos forçam a fazer estas coisas; mas eu vos darei terras férteis, por serdes aliados sem recursos, e vos estabelecerei em campos abundantes...».

Embora esta questão seja frequentemente sublinhada, nem sempre foi devidamente avaliada pela historiografia moderna que apresenta geralmente uma interpretação demasiado dependente da visão que enforma os textos clássicos.

$\mathrm{Na}$ realidade, como se sublinha bem neste passo, não se trata precisamente de um problema de uma carência de terras, mas de uma questão relativa à qualidade das mesmas, e por isso se acentua a oposição entre a «esterilidade do solo» que caracteriza o território ocupado pelos lusitanos e as «terras férteis» que lhes são prometidas $^{10}$.

Naturalmente, a razão pela qual os Lusitanos se debatem com essa difícil situação reside no facto de o poder romano ter desenvolvido, no Sul da Hispânia, em particular numa boa parte do território da atual Andaluzia, uma política de acesso aos solos férteis que privilegiou os povos aliados.

${ }^{9}$ Crudelissima ac superbissima gens sua omnia suique arbitrii facit; cum quibus bellum, cum quibus pacem habeamus, se modum imponere aequum censet. Circumscribit includitque nos terminis montium fluminumque, quos non excedamus, neque eos, quos statuit, terminos observat (Liv. 23.44.5).

${ }^{10}$ Para a análise desta questão e deste passo em particular v. Sayas Abengochea 1989, esp. 711-14. 
Entre eles, Apiano refere os Blasto-fenícios e Cónios e certamente neles também se integram os Turdetanos, entre os quais podemos encontrar, como arquétipo, Astolpas, representante de uma próspera elite colaboracionista. Deste modo, essa região proverbialmente rica no domínio agrícola torna-se progressivamente inacessível aos que não aceitam a influência romana. $\mathrm{O}$ contraste entre a natureza do território controlado por romanos e lusitanos transparece igualmente num dos tópicos que a literatura associa a estes últimos, o facto de estes serem populações que habitam essencialmente as zonas montanhosas. Naturalmente, esta circunstância não pode resultar de uma opção expressamente feita por essa entidade, mas decorre do próprio processo de conquista e da pressão militar que os romanos exercem sobre eles, empurrando-os para essa situação.

Voltando ao texto do discurso de Aníbal, parece claro que, na ideia do patavino, o mundo lusitano se apresenta como uma realidade pobre e agreste, circunstância que anda associada ao carácter belicoso deste povo. Por essa razão, a promessa do general púnico de uma campanha proveitosa, em tudo diferente das difíceis ações anteriores in vastis Lusitaniae Celtiberiaeque montibus ${ }^{11}$, pode servir precisamente para sublinhar a dicotomia entre a pobreza destes e a riqueza dos povos da Cisalpina e da Itália.

Pode colher-se nos textos clássicos uma ideia: a da existência de uma espécie de determinismo que faz com as populações das regiões mais inóspitas não sejam apenas mais pobres, mas também, por essa razão, constroem um outro modelo de vida, no qual a prática da pilhagem constitui uma resposta às suas carências. Em consequência disso, desenvolveram capacidades especiais, estando, por isso, mais preparadas para a guerra, uma vez que o seu modelo de sobrevivência passa por aquilo que as fontes designam de forma pejorativa como latrocinium, o «bandoleirismo».

Esta forma de caracterizar o mundo lusitano teve uma ampla difusão na literatura clássica, continuada por um conjunto muito diversificado de considerações na historiografia moderna, especialmente nas últimas décadas ${ }^{12}$.

A alusão a estes dois povos ibéricos deve corresponder, nestas circunstâncias, a uma elaboração histórica marcada pelo anacronismo. Tito Lívio recupera os seus conhecimentos da realidade histórica subsequente (especialmente da segunda metade do séc. II a. C., mas também no séc. I a. C.), em que os confrontos com Lusitanos e Celtiberos se registam amplamente nas fontes, deixando a impressão de que estes povos colocaram em sérias dificuldades os exércitos de Roma. Deste modo, também os púnicos teriam

${ }^{11}$ Liv. 21.43.8.

12 Sobre o tema v. García y Bellido 1945; Clavel-Lévêque 1978; Sayas Abengochea 1989; Vallejo Girvés 1994; Sánchez-Corriendo 1997; Gómez Fraile 1999; Sánchez Moreno 2006; Riess 2011; Vives Ferrer 2015. 
enfrentado tais dificuldades, que a empresa que se seguia seria certamente mais fácil e proveitosa.

A inclusão da referência a essas entidades resulta mais do processo de construção retórica e dos elementos nela incluídos, do que de circunstâncias históricas concretas, reportáveis a um período precedente, em que se registariam conflitos específicos entre púnicos, celtiberos e lusitanos. Esta observação pretende, pois, chamar a atenção para o contexto do que se apresenta como a primeira referência aos Lusitanos e que marcaria a forma como esta entidade entra na História. Há que ponderar sempre as informações relativas a períodos precedentes e em particular quando constituem elementos típicos de uma narrativa histórica, como os discursos, naturalmente sempre pontuados por visões que correspondem mais à perspetiva do tempo que às condições vividas alguns séculos antes. Neste caso uma discrepância de dois séculos pode fazer bastante diferença e esta pode passar despercebida a quem transmite a informação. A construção discursiva de Lívio poderá ser tributária de relatos correspondentes aos conflitos de período cesariano, que de alguma forma evocam a expressão usada por Tito Lívio para definir a ação do exército como uma pouco proveitosa perseguição de rebanhos nas vastas montanhas da Lusitânia e da Celtibéria (in vastis Lusitaniae Celtiberiaeque montibus pecora consectando). Esta referência não deixa de recordar algumas circunstâncias particulares da incursão de César, na Lusitânia, mais concretamente no monte Hermínio, conhecidas pelo texto Díon Cássio ${ }^{13}$, onde se explica como os habitantes dessa região procuraram perturbar a ação dos exércitos romanos enviando à frente os seus rebanhos.

\section{DÉcimo Júnio Bruto entre os Brácaros: olHares SObre o He- ROÍSMO FEMININO NA HISPÂNIA.}

A construção de uma imagem do mundo ocidental parece resultar igualmente com bastante clareza do conhecido episódio da incursão de Décimo Júnio Bruto no mundo galaico, a que se dedica aqui uma especial atenção. Este é-nos apresentado, de forma mais sugestiva, por Apiano, o qual inclui na sua narrativa alguns aspetos que contribuem para consolidar a ideia de que este autor transmite uma imagem complexa e, por assim dizer, mais equilibrada de que outros autores, como Tito Lívio, na qual se cruzam aparentemente perspetivas contrastantes a respeito dos povos locais.

Há alguns anos, analisando precisamente a imagem que este autor de língua grega nos transmite na sua obra, especialmente na dedicada às guerras na Hispânia, Gómez Espelosín ${ }^{14}$ chamava a atenção para esses contrastes: de um lado pesaria a sua admiração por Roma e pelo império que construiu, pelo seu

\footnotetext{
${ }^{13}$ D.C. 37.52 .5 .

${ }^{14}$ Especialmente em Gómez Espelosín 2009.
} 
contributo para a construção de um mundo mais unitário e integrador, mais pacífico e desenvolvido, correspondendo bem à ideologia que o modelo augustano tinha elaborado e do qual participam igualmente outros autores na sua situação, como Estrabão; do outro a simpatia manifestada por alguns aspetos do carácter ou atuação dos opositores de Roma.

Apesar de este autor grego se incluir entre os que admiram as realizações dos romanos, reflete bem a complexidade da sua situação cultural, revelando perspetivas sobre os acontecimentos que podem parecer contraditórias. Ainda que a dicotomia entre civilizado e bárbaro estruture a sua visão deste mundo hispânico, com natural preferência pelo que genericamente caracteriza o primeiro, não deixa de valorizar alguns aspetos concretos de um mundo que, em certa medida, constitui a sua antítese. E esta sua posição radica, estruturalmente, na sua dupla identidade, a de romano e de alexandrino ${ }^{15}$.

Depois de descrever largamente as circunstâncias e intenções com que se realizava esta ação, o texto de Apiano refere-se por duas vezes aos confrontos e às suas circunstâncias, repetindo essencialmente as mesmas ideias. No primeiro (Apian. Hisp. 71), escreve: «Tendo certamente isto em consideração, (Décimo Júnio Bruto) devastou tudo o que estava pelo caminho; (viu) mulheres combatendo com os homens, perecendo ao seu lado, sem soltarem um gemido, mesmo no momento do golpe» ${ }^{16}$. O segundo passo reproduz termos e expressões deste, referindo os seus aspetos essenciais: a combatividade desse povo, o papel das mulheres na guerra e forma espantosa como enfrentam o combate e reagem ao golpe fatal ${ }^{17}$. No entanto, a esta informação junta uma outra circunstância que parece impressioná-lo particularmente: «De todas as mulheres capturadas, umas infligiram-se a morte, outras mataram os filhos com as próprias mãos, preferindo de longe a morte ao cativeiro (App. Hisp. 72)».

Conjugam-se, portanto, nestas breves narrativas, vários aspetos que diferenciam culturalmente o mundo greco-latino destas comunidades galaicas ${ }^{18}$. Em primeiro lugar, surpreende o papel das mulheres nos contextos de guerra, impossível de imaginar para um grego. Os exércitos eram, por sua natureza, constituídos exclusivamente por homens e o papel da mulher no contexto social

${ }^{15}$ Sobre a importância desta condição na construção da sua história v. Bucher 2000, passim.

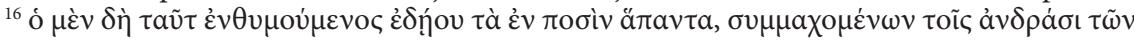

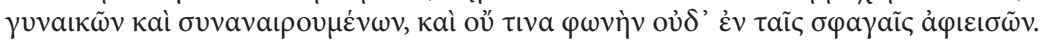

${ }^{17}$ App. Hisp. 72: «(os Brácaros) eram um povo [muito belicoso], a par das mulheres armadas também eles combatiam e morriam com bravura, não cedendo nenhum deles, não voltando as costas e não soltando um grito. Das mulheres capturadas, umas mataram-se a elas próprias, outras provocaram a dos seus filhos com as suas próprias mãos, prezando mais a morte que o cativeiro».

${ }^{18}$ Esta passagem de Apiano foi analisada, sob diversas perspetivas, nomeadamente em Martínez Lopes 1986, 391; Gómez Espelosín 1993, 111; Alonso Troncoso 1996, 61. 
não passava nunca pela participação em atividades como a guerra. Por esta ra-

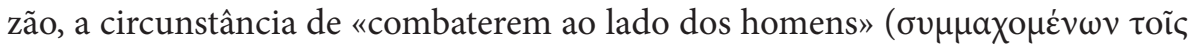
ả $\delta \delta \rho \dot{\sigma} \sigma$ ) coloca-as em paralelo com a condição masculina e com a sua natureza, o que seria necessariamente considerada uma situação estranha às tradições do mundo «civilizado».

Em segundo lugar, sobressai a bravura com que elas enfrentavam a morte e especialmente o facto de não «soltarem um gemido, mesmo no momento do golpe». Para além do facto de o combate ser, por natureza, acompanhado de incentivos e alarido, espera-se que o momento em que o soldado é atingido seja marcado ao menos por uma manifestação de dor. Deste modo, sendo insólito, para Apiano, que estas mulheres enfrentem de um modo tão silencioso essa situação, não deixará de ser valorizado, pelo menos em determinadas leituras, como uma marca de sentido positivo ${ }^{19}$.

O contraste entre comportamento feminino em situações de conflito em alguns povos bárbaros e a realidade grega ou romana regista-se com alguma frequência e encontra-se bem documentada em outras narrativas do processo de conquista da Hispânia, sendo possível compreender diferentes facetas desse heroísmo feminino. Analisam-se, de seguida, algumas das ocorrências mais sugestivas, registadas em Iliturgi, Sagunto, Astapa ${ }^{20}$ e Salmantica.

No que diz respeito à participação feminina no combate, o mais antigo episódio é transmitido por Tito Lívio e reporta-se ao ataque romano a Iliturgi ${ }^{21}$, no ano 206 a. C., no qual se dá conta que as mulheres e crianças ajudavam os homens na guerra, providenciando armamento ou transportando pedras para a reconstrução das muralhas (Liv. 28.19.13) ${ }^{22}$.

Quanto ao temor de enfrentar a servidão, um exemplo paralelo regista-o, para além de Lívio, o próprio Apiano, ao descrever a tomada da cidade de Astapa, que os romanos atacam por se manter fiel aos cartagineses: «E comprometeram com um juramento os cinquenta melhores a que, logo que a cidade fosse tomada, eliminariam as mulheres e crianças, lançariam fogo (à pira) e, de

${ }^{19}$ Pode encarar-se a possibilidade de esta elevada belicosidade ou do extremismo das suas atitudes ser precisamente uma marca da sua cultura bárbara - v., a este respeito, algumas observações em Marco 1993 e Aguilera 2012, 545-46. Não parece, no entanto, que seja esta vertente interpretativa seja a mais adequada neste caso.

${ }^{20}$ Uma análise comparativa destes três primeiros casos de heroísmo trágico pode encontrar-se em Pelletier 1987.

${ }^{21}$ Disputada longamente a sua localização, foi estabelecida em meados do séc. XX, situando-se nas proximidades de Mengíbar (Jaén) a cidade romana (Blanco et Lachica 1960). Para os mais recentes projetos de investigação no sítio do Cerro de Maquiz e sua envolvência v. Lechuga et al. 2015, tendo-se anunciado descobertas de vestígios materiais (glandes, pontas de catapulta) que corresponderiam ao cerco de Cipião.

${ }^{22}$ Sobre estes acontecimentos, considerando fundamentalmente o papel das mulheres, $\mathrm{v}$. Martínez López 1991, esp. 249-50; Ruiz Montero et Jiménez 2008, 112. 
seguida, matar-se-iam a si próprios» (App. Hisp. 33) ${ }^{23}$. Este autor sublinha, no final, a atitude que tal comportamento suscitou no general romano, Márcio, o

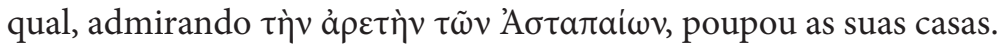

Em Lívio ${ }^{24}$ explica-se que essa situação dramática, acarretando inevitavelmente a perda da liberdade, poderia acabar de dois modos: ou com a morte honrosa (morte honesta) ou com a vergonhosa servidão (infami seruitute) e, naturalmente, só a primeira atitude era digna ${ }^{25}$. De qualquer modo, como já sublinhou Agnés Pelletier ${ }^{26}$, a perspetiva de Lívio em relação a esta ocorrência encerra aspetos distintos e a valorização eventualmente positiva deste comportamento por outros autores dilui-se na constatação de que ela resulta mais da sua má consciência, da conscientia scelerum ${ }^{27}$, que se consubstanciava não tanto no facto de terem sempre estado ao lado púnico, mas antes por se entregaram ao bandoleirismo (latrocinio), realizando incursões em território dos aliados de Roma (excursiones in finitimum agrum sociorum populi Romani; Liv. 28.22.3). Deste modo, na perspetiva liviana, a atitude dos habitantes de Astapa nada tinha de particularmente digno de apreço, mas resultava de sentimentos menos nobres, determinados pelas circunstâncias históricas em que o cerco ocorria.

A confrontação das duas narrativas, permite constatar que o texto de Apiano reflete de forma mais evidente a duplicidade de perspetiva que a literatura clássica assume perante as comunidades que se confrontam com o mundo romano, onde esporadicamente se suscita uma admiração por alguns traços do seu carácter. E Apiano encontra-se, naturalmente, menos comprometido com a defesa da superioridade moral do imperialismo romano no confronto com os povos que vai submetendo.

Também neste caso de Astapa se tem discutido a eventual dependência desta narrativa de alguns topoi da literatura clássica, nomeadamente os que relatam os cercos de Sagunto pelos cartagineses (pertencente ao mesmo autor, Liv. 21.14) e o de Abido por Filipe V (transmitida em Pol. 16.30-34)28. Inevitavelmente, estas narrativas têm sempre algo de comum e alguns desses aspetos particulares, no caso a escolha de 50 homens que, perante juramento, se comprometem a empreender uma série de ações decisivas ${ }^{29}$, podem constituir uma componente

${ }^{23}$ Corresponde a Liv. 28.22. Sobre este episódio v. Eckstein 1995, 48-51; Martínez López 1991, 249-50; Gómez Espelosín 2009, 235-37.

${ }^{24}$ Liv. 28.22.9.

${ }^{25} \mathrm{O}$ passo pertinente diz: /.../ ut memores libertatis, quae illo die aut morte honesta aut seruitute infami finienda esset.

${ }^{26}$ Pelletier 1989, 113; no mesmo sentido, Gómez Espelosín 2009, 236.

${ }^{27}$ Liv. 28.22.5.

${ }^{28}$ Especialmente em Walsh 1970, 194-95; Walbank 1971, 60.

${ }^{29}$ Pol. 16.31; Liv. 28.22.7; App. Hisp. 33. 
recuperada de outras descrições de episódios similares ${ }^{30}$.

Sobre a situação que estes acontecimentos encerram se pronunciou também García Riaza ${ }^{31}$, sustentando que, apesar de algumas afinidades o caso saguntino descrito reúne um conjunto de especificidades que conferem um dramatismo peculiar a estas diferentes narrativas.

Do mesmo modo, as referências da historiografia clássica ao cerco de Salmantica, que acaba saqueada por Aníbal, constituem um exemplo da intervenção feminina em contextos bélicos, mas, neste caso também com peculiaridades que lhe conferem uma grande verosimilhança. Mais do que Plutarco ${ }^{32}$, é especialmente no relato de Polieno ${ }^{33}$ que se sublinha o papel combativo das mulheres, as quais, depois de conseguirem esconder as espadas dos inimigos, entregam uma parte aos seus homens e combatem também ao lado deles. Sublinha-se, neste caso, a circunstância de não ser imaginável para os púnicos (e, de igual forma, para gregos e romanos), por razões culturais, o envolvimento delas neste tipo de ações.

De uma maneira geral, o heroísmo feminino é especialmente apreciado em narrativas que envolvem povos bárbaros ocidentais, encontrando-se bem documentado na literatura clássica, mesmo fora da Hispânia. Neste sentido, podem comparar-se estas particularidades com as que evidenciam mulheres germânicas, em especial nos relatos de Tácito e Estrabão. Dessa confrontação resulta claro que a coragem feminina revelada em território dos Brácaros vai além da das suas congéneres germânicas: não acompanham apenas os maridos na guerra, mas pegam efetivamente em armas; e o temor do cativeiro por parte das mulheres nobres não é apenas consciente ${ }^{34}$, mas chega ao ponto extremo de infligirem a morte aos filhos e si próprias ${ }^{35}$.

Esta facilidade com que estas mulheres se dispõem a enfrentar a morte recorda o texto com que mesmo Apiano descreve os últimos momentos da resistência de Numância (App. Hisp. 96-97): «Mas eles deixaram passar o dia, acordando que muitos deles ainda se agarravam à liberdade e desejavam tirar-se a sua própria vida. (97) Tamanho era o amor pela liberdade e pela bravura nesta cidade bárbara e pequena $»^{36}$.

${ }^{30}$ Em relação a estas considerações se levantaram algumas objeções, especialmente em Eckstein 1995, 48-51, onde se sustenta que o texto de Lívio depende mais da descrição que Políbio faz do cerco de Astapa.

${ }^{31}$ García Riaza 1998-1999, 208-9.

32 Plut. Moral. 248E-249B.

${ }^{33}$ Polyaen. 7.48 .

34 Tac. Ger. 8.

${ }^{35}$ App. Hisp. 72. Para uma circunstanciada análise da imagem da mulher germânica nos dois autores citados v. especialmente Gallego Franco 1999, 62-63, onde se analisa genericamente o papel feminino na guerra e as suas atitudes perante o cativeiro, pondo-se em paralelo precisamente com o que ocorre na Hispânia setentrional.

${ }^{36}$ Para uma análise deste episódio enquanto exemplo de apego à liberdade da parte dos povos hispânicos v. Gómez Espelosín (2009, 237-38), onde se considera igualmente a questão 
Deparamo-nos sempre com a dificuldade em estabelecer até que ponto estas narrativas não se inserem numa tradição literária que veicula determinadas imagens que verificamos repetirem-se em outros contextos - como é o caso das considerações a respeito das mulheres germânicas, segundo Tácito e Estrabão ${ }^{37}$.

Esse heroísmo assume-se como realidade que se transmite, por regra, como característico de um coletivo, tendo como atores uma comunidade mais ou menos extensa, com frequência todo o conjunto dos habitantes de uma cidade afetada por um conflito com Roma. Deste modo, só raramente essa realidade assume um carácter individual. Embora tanto uma circunstância como outra sejam, no contexto literário, pertinentes para a caracterização dos povos hispânicos, a primeira contribui de forma mais substancial para afirmar o carácter das comunidades locais e definir a sua alteridade.

No contexto em que a análise da historiografia moderna tem sublinhado precisamente o quadro mental em que as narrativas de conquista se inserem, estes exemplos mostram a diversidade das perspetivas e a complexidade que envolve uma análise deste conjunto de informação literária. Nunca se pode perder de vista que a valorização das qualidades militares dos opositores de Roma constitui, em si, uma forma de acentuar o valor da sua empresa imperialista. Em certa medida, também a exaltação de certos aspetos da cultura destes povos não questiona de modo algum a superioridade (militar e moral) romana nem a legitimidade do seu programa expansionista. Por isso mesmo, a extensão da difusão de uma cultura de que gregos e romanos se orgulham, constitui também uma vantagem para os povos submetidos que, por esta via, são promovidos a uma outra condição, mais elevada.

Trata-se, no fundo, de uma situação que acaba por ter paralelos nos desígnios do programa expansionista português que, ao alargar a fé e o império, encara o contacto com uma boa parte desses povos com um contributo decisivo para a sua salvação.

da eventual dependência de Apiano em relação às suas fontes.

${ }^{37}$ Gallego Franco $(1999,62)$ analisa a informação das fontes clássicas que aludem às mulheres germânicas que acompanham os homens em campanha, lutam com eles, defende com especial força a sua liberdade. 


\section{Bibliografia}

Aguilera Durán, T. 2012. "Una visión historiográfica alternativa: la deconstrucción del estereotipo del bárbaro prerromano." Antesteria 1:543-55.

Alonso Troncoso, V. 1996. "Primeras etapas en la conquista romana de Gallaecia." Militaria 8:53-66.

Alvar Ezquerra, J. 1997. “Héroes ajenos: Aníbal y Viriato.” In Héroes y antihéroes en la Antigüedad clásica, eds. J. Alvar e J. Ma. Blázquez, 137-53. Madrid: Cátedra.

Blanco Frejeiro, A. e G. Lachica Casinello. 1960. "De situ Iliturgis." Archivo Español de Arqueologia 33 (101-102):193-96.

Bermejo Barrera, J. C. 1986. "El erudito y la barbarie." In Mitología y Mitos de la Hispania Prerromana. Vol. 2, 13-43. Madrid, Akal.

Bucher, G. S. 2000. “The Origins, Program, and Composition of Appian's Roman History." Transactions and Proceedings of the American Philological Association 130:411-58.

Clavel-Lévêque, M. 1978. "Brigandage et piraterie: représentations idéologiques et pratiques impérialistes au dernier siècle de la République." Dialogues d'histoire ancienne 4:17-31.

Cruz-Andreotti, G. 2002. "Iberia e iberos en las fuentes histórico-geográficas griegas: una propuesta de análisis." Mainake 24:153-80.

Dauge, Y. A. 1981. Le Barbare. Recherches sur la conception romaine de la barbarie et de la civilisation. Bruxelles: Latomus.

Duplá, A., M. Otxoa e C. Ortiz de Urbina Montoya. 1988. “Civilización y barbarie en la Historiografía republicana: el caso de Hispania y los pueblos del norte." In Actas del Congreso de Historia de Euskal Herria, I. II Congreso Mundial Vasco, 165-72. San Sebastián: Txertoa.

Eckstein, A. M. 1995. Moral Vision in the Histories of Polybius. Berkeley: University of California Press.

Gallego Franco, H. 1999. "La imagen de la 'mujer bárbara': a propósito de Estrabón, Tácito y Germania.” Faventia 21 (1):55-63.

García Moreno, L. A. 2005. "Polibio y la creación del estereotipo de lo Hispano en la etnografía y la historiografía helenísticas." In Polibio y la Península Ibérica, ed. J. Santos e E. Torregaray, 339-58. Bilbao: Universidad del País Vasco.

1989. "La Hispania anterior a nuestra era: verdad, ficción y prejuicio en la Historiografía antigua y moderna." In Actas del VII Congreso Español de Estudios Clásicos. Vol. 3, 17-43. Madrid: Sociedad Española de Estudios Clásicos / Editorial de la Universidad Complutense. 
—_ 1987. "Presupuestos ideológicos de la actuación de Roma durante el proceso de la conquista de Hispania." Gerión 5:211-44.

García Riaza, E. 1998-1999. “Derecho de guerra romano en Hispania (218-205 a. C.)." Memorias de Historia Antigua 19-20:199-224.

García y Bellido, A. 1945. "Bandas y guerrillas en las luchas con Roma." Hispania 21:547-604.

Gómez Espelosín, F. J. 2009. "Contradicciones y conflictos de identidad en Apiano." Gerión 27:231-50.

__ 1996. "Estrategias narrativas en la Historia de Apiano: Algunos ejemplos." Annali della Scuola Normale Superiore di Pisa. Classe di Lettere e Filosofia, série 4, 1 (1):103-17.

—_ 1993. "La imagen del bárbaro en Apiano: La adaptabilidad de un modelo retórico." Habis 24:105-24.

Gómez Fraile, J. Ma. 1999. "Mercenariado y bandolerismo en Celtiberia. Dos cuestiones desenfocadas." In IV Simposio sobre los Celtíberos. Economía. Homenaje a J.L. Argente Oliver (Daroca, Septiembre 1997), ed. F. Burillo, 503-9. Zaragoza: Institución Fernando el Católico.

González Ballesteros, I. 2009. "El estereotipo del bárbaro y la imagen de la civilización en el occidente romano en la Geografía de Estrabón”. Espacio Tiempo y Forma 22, série 2, 22:249-60.

Gracia, F. 2009. Furor barbari! Celtas y germanos contra Roma (ss. IV a.C.-I d.C.). Barcelona: Versatil.

Hall, E. 1989. Inventing the barbarian: Greek self-definition through Tragedy. Oxford: Clarendon Press.

Hoz Bravo, J. de. 2000. "La etnografía de los pueblos de Iberia en Diodoro V 33 34 y el problema de sus fuentes." In Epieikeia. Studia graeca in memoriam Jesus Lens Tuero, ed. M. Alganza, 221-38. Granada: Athos-Pergamos.

Jones, T. e A. Ereira 2008. Roma y los bárbaros. Una historia alternativa. Barcelona: Critica.

Manchón Gómez, R. 2013. "La arenga de Aníbal en la batalla del Tesino (Liv. XXI 43-44) como ejemplo del munus oratoris de Tito Livio." Florentia Iliberritana 24:87-109.

Martínez López, C. 1991. "Las mujeres en la conquista y romanización de la Hispania Meridional." Florentia Iliberritana 1:245-54.

.1986. "Las mujeres de la Península Ibérica durante la conquista cartaginesa y romana." In La Mujer en el mundo antiguo: Actas de las V Jornadas de Investigación Interdisciplinaria: Seminario de Estudios de la Mujer, ed. E. Garrido González, 387-96. Madrid: Universidad Autónoma de Madrid.

Lechuga Chica, M. Á., J. P. Bellón Ruíz e C. Rueda Galán. 2015. "Nuevas 
propuestas de actuación para el estudio del oppidum de Iliturgi desde la arqueología del territorio." Revista Atlántica-Mediterránea 17:211-21.

Marco Simón, F. 1993. "Feritas Celtica: imagen y realidad del bárbaro clásico." In Modelos ideales y prácticas de vida en la Antigüedad clásica, ed. É. Falqué e F. Gascó, 141-66. Sevilla: Universidad de Sevilla / Universidad Internacional Menéndez Pelayo.

Mitchell, L. 2007. Panhellenism and the barbarian in Archaic and Classical Greece. Swansea: The Classical Press of Wales.

Pelegrín, J. 2003. Barbarie y frontera: Roma y el Valle Medio del Ebro durante los siglos IIII a.C. Zaragoza: Universidad de Zaragoza.

Pelletier, A. 1987. "Sagonte, Iliturgi, Astapa: trois destins tragiques vus de Rome." Mélanges de la Casa de Velázquez 23 (1):107-24.

Plácido Suárez, D. 1987-1988. "Estrabón III: el territorio hispano, la geografía griega y el imperialismo romano.” Habis 18-19:243-56.

Revell, L. 2009. Roman imperialism and local identities: Cambridge: Cambridge University Press.

Riess, W. 2011. "The roman bandit (latro) as criminal and outsider." In Social relations in the Roman World, ed. M. Peachin, 693-714. Oxford: Oxford University Press.

Ruiz Montero, C., e A. M. Jiménez. 2008. "Mulierum virtutes de Plutarco: aspectos de estructura y composición de la obra.” Myrtia 23:101-20.

Salinas de Frías, M. 1999. “De Polibio a Estrabón. Los celtas hispanos en la historiografía clásica." In Homenaje al profesor Montenegro. Estudios de Historia Antigua, ed. A. Alonso, S. Crespo, T. Garabito e Ma E. Solovera, 191-203. Valladolid, Secretariado de Publicaciones e Intercambio Editorial / Universidad de Valladolid.

. 1998. "La guerra de los cántabros y astures, la etnografía de España y la propaganda de Augusto." In "Romanización" y "Reconquista" en la Península Ibérica: nuevas perspectivas, eds. $\mathrm{M}^{\mathrm{a}}$ J. Hidalgo, D. Pérez, e M. J. R. Gervás, M.J.R., 155-70. Salamanca: Universidad de Salamanca.

Sánchez-Moreno, E. 2011. "De la resistencia a la negociación: acerca de las actitudes y capacidades de las comunidades hispanas frente al imperialismo romano." In De fronteras a provincias. Interacción e integración en Occidente (ss. III-I a. C.), ed. E. García Riaza, 97103. Palma de Mallorca: Universitat de les Illes Balears.

2006. "Ex pastore latro, ex latrone dux... Medioambiente, guerra y poder en el occidente de Iberia." In War and territory in the Roman World, ed. T. Ñaco del Hoyo e I. Arrayás Morales, 55-79. Oxford: Archeopress.

Sánchez Moreno, E. e T. Aguilera Durán. 2013. “Bárbaros y vencidos, los otros en la conquista romana de Hispania. Notas para una deconstrucción 
historiográfica." In Debita Verba. Estudios en homenaje al profesor Julio Mangas Manjarrés, ed. R. M. Cid López e E. García Fernández, 225-44. Oviedo: Servicio de Publicaciones de la Universidad de Oviedo.

Sánchez-Corriendo Jaén, J. 1997. “¿Bandidos lusitanos o pastores trashumantes? Apuntes para el estudio de la trashumancia en Hispania." Hispania Antiqua 21:69-92.

Sayas Abengochea, J. J. 1989. "El bandolerismo lusitano y la falta de tierras." Revista de la Facultad de Geografía e Historia 4:701-14.

Thollard, P. 1987. Barbarie et civilisation chez Strabon. Étude critique des Livres III et IV de la Geographie. Paris: Les Belles Lettres.

Vallejo Girvés, M. 1994. "El recurso de Roma al bandidaje hispano." Espacio Tiempo y Forma 7:165-73.

Vives Ferrer, G. 2015. "El fenómeno del bandolerismo como sublevación contra Roma: el caso de Hispania en la época republicana." Antesteria 4:187-97.

Walbank, F. W. 1971. “Livy's Fourth and Fifth Decades.” In Livy, ed. T. A. Dorey, 47-72. London / Toronto: Routledge / Kegan Paul.

Walsh, P. G. 1970. Livy: his historical aims and methods. Cambridge: Cambridge University Press.

Woolf, G. 2011. Tales of the Barbarians. Ethnography and Empire in the Roman West. Oxford: Wiley-Blackwell. 